\title{
LA PEDAGOGÍA DE EMILE DURKHEIM
}

\author{
EMILE DURKHEIM'S \\ PEDAGOGY
}

Luis Alberto Carmona Sánchez
https://orcid.org/0000-0002-5319-9645

Recibido: abril 4, 2020 - Aceptado: mayo 15, 2020.

\section{RESUMEN}

Este artículo busca exponer el planteamiento pedagógico que aporta el francés David Emilie Durkheim (1958-1917), desde la Sociología de la Educación, para hacer efectivo el proyecto que la Tercera República Francesa se hubo de forjar sobre la nueva sociedad y el nuevo ser social que pretendía alcanzar. Para tal propósito, se examinan los fundamentos conceptuales que configuran el planteamiento sociológico del autor en torno a la Pedagogía y la Educación, y su relación con el proyecto unificado teórico-práctico de nueva sociedad y nuevo ser social, presentada en cuatro aspectos: I. El contexto: definición y Tercera República Francesa; II. La condición: la Pedagogía; III. El medio: la Educación; IV. El propósito de la Pedagogía: la sociedad. El trabajo aporta una revisión teórica e interpretativa a la contribución de Durkheim al campo de la Sociología de la Educación, destacando la connotación política que contienen sus ideas en este campo, y la enseñanza metodológica considerada vigente, la cual sugiere el desarrollo teórico y práctico de la Pedagogía, ante todo comprendiendo las dinámicas sociales y las exigencias morales particulares de cada sociedad, antes que la importación aconceptual y ahistórica de modelos pedagógicos inflexibles.

Palabras clave: autoridad, educación, moral, Pedagogía, sociedad, ser social, individuo, tradición.

1 Magister en Filosofía, Universidad de Caldas. Profesor Integrante Grupo de investigación en ética empresarial ETHOS, Universidad Nacional de Colombia, sede Manizales.

luacarmonasa@unal.edu.co 


\begin{abstract}
The article seeks to expose the pedagogical approach contributed by the French David Emilie Durkheim (1958-1917), from the sociology of education, to make effective the project that the French Third Republic had to forge on the new society and the new social being that he intended. For this purpose, the conceptual foundations that shape the author's sociological approach to pedagogy and education are examined, as well as its relationship with the unified theoretical-practical project of a new society and new social being, which is presented in four aspects. : I. The context: definition and the Third French Republic; II. The condition: pedagogy; III. The means: education; IV. The purpose of pedagogy: the society. The article provides a theoretical and interpretative review of Durkheim's contribution to the field of sociology of education, highlighting the political connotation that his ideas contained in this field, and the methodological teaching considered current, which suggests the theoretical and practical development of pedagogy, first of all by understanding the social dynamics and the particular moral demands of each society rather than the nonconceptual and ahistorical importation of inflexible pedagogical models.
\end{abstract}

Keyword: Authority, Education, Moral, Pedagogy, Society, Social Being, Individual, Tradition.

\title{
INTRODUCCIÓN
}

Para qué educar a la población joven es una pregunta relevante que se hacen en primera instancia los maestros y todo el marco educativo, y que necesariamente deben formularse los gobiernos centrales de cada país. Educar para la autonomía, educar para socionomía, o para proporcionarle fuerza de trabajo intelectual y práctica a la sociedad, son algunas de las posibles respuestas. Ahora, la siguiente pregunta es ¿y cómo hacerlo? Como lo indique la Pedagogía. Esta es la respuesta frente al cómo educar, siendo el reto siguiente determinar qué es la Pedagogía. De todo ello se encarga Durkheim.

El sociólogo francés David Emilie Durkheim (1958-1917) aporta uno de los planteamientos más relevantes sobre la Pedagogía y la educación en el marco de su Sociología de la Educación. Toda su obra se fundamenta y transversaliza por las implicaciones políticas de cuño conservador que conlleva su Sociología. En este sentido, la Pedagogía ha de ser el faro teórico orientador de la práctica educativa. La Pedagogía termina por ser el móvil racional de la continua practicidad del educador para que, y esto es lo más destacable, la población adulta implemente los principios de conducta a la población joven, quienes deberán terminar por garantizar el orden de la sociedad y, por tanto, su cohesión y tradición, tan lesionadas estas a raíz de la Revolución Francesa.

La práctica educativa y su correspondiente orientación teórica por parte de la Pedagogía, como podrá advertirse, implican para Durkheim una unidad que conducirá al ejercicio real de consolidación de un proyecto nuevo de sociedad. Este fue su propósito, y lo que el presente escrito evidencia. El sociólogo francés, heredero en primer grado de la Sociología de Comte, asume el encargo de liderar el proyecto pedagógico que lleve a la consolidación de la nueva sociedad y el nuevo ser social que la Tercera República Francesa pretende concretizar.

¿Cuál es la educación que la sociedad francesa necesita para devenir en nueva sociedad? La homogeneización y la solidaridad son fundamentos del proyecto pedagógico y político de la Tercera República Francesa, de Durkheim. Cada planteamiento suyo va decantando 
el trayecto que la sociedad francesa deberá recorrer, como deshacer los pasos ilustrados que avanzaron individuos en su pretensión de autonomía, y rehacer los correspondientes a los de un ser social solidario y obediente que, en lugar de revolucionar la tradición y a riesgo nuevo de caer en anarquías morales e intelectuales, la preserve en el marco de un proyecto colectivo.

Para esto, Durkheim clarifica el contexto en el que se inserta el proyecto de la nueva sociedad pretendida, evidencia la condición para lograrlo, deja claro el medio que conduce a su realización y, finalmente, determina el propósito de la Pedagogía como colofón de su planteamiento en torno a ella y el mayor aporte teórico-práctico al proyecto de sociedad que se propuso subvencionar. La exposición y discusión de cada uno de estos elementos son los constitutivos del presente trabajo, que tiene como propósito implícito llamar la atención sobre la importancia de reflexionar en torno a los fines y las maneras de la educación en un contexto particular. El proyecto educativo y de sociedad será consecuencia natural de la dinámica misma de cada sociedad. Durkheim lo probó con su sociedad francesa, legando más una metodología de investigación y una forma de reflexionar en el campo de la educación, que un modelo a implementar con desconocimiento total de las particularidades históricas de la sociedad a la que responde como producto, orientadora de su respectiva práctica educativa, y configuradora de una identidad de hombre y de sociedad. A la Educación y la Pedagogía, en unidad, les corresponde aportar planteamientos propios y acordes con los contextos sociales y materiales de vida de la sociedad que pretenden construir.

\section{EL CONTEXTO: DEFINICIÓN Y TERCERA REPÚBLICA FRANCESA}

Entre antropólogos no se ha logrado un consenso sobre lo que es el concepto de cultura para el campo de su disciplina (Pérez, 1995). El esfuerzo por aprehender conceptualmente la vida misma del hombre en lo material e inmaterial, por ahora, solo ha arrojado amplia literatura académica con presunciones de directriz práctica. La Pedagogía experimenta igual situación de polivalencia, lo que enriquece tanto la discusión académica como empobrece, o por lo menos limita, el hacer práctico del educador.

Con base en lo anterior es preciso señalar que, en términos técnicos, la Pedagogía puede concebirse como el «estudio sistemático tanto de la metodología como de las técnicas que orientan la práctica docente» (Carmona, 2016, 1). No obstante, decanto la comprensión por la idea originaria de la Pedagogía en la perspectiva de la orientación del hombre natural por la ruta de la cultura, es decir, en tanto proceso de humanización del hombre que lo conduce a la praxis humana, al saberse y hacerse a sí mismo. La primera definición empobrece el discurso de la Pedagogía a técnica, a meta-teoría o a ciencia, siendo del resorte reflexivo tan solo de expertos pertenecientes a escuelas o facultades de educación; sin embargo, el sacerdote, por el hecho de serlo, no goza de mayor cercanía a Dios. Por su parte, con la segunda acepción de Pedagogía aproximo su reivindicación como Filosofía de la Educación, por ser la que «formula los fines de la educación, las metas que deben alcanzarse» (Abbagnano, Visalberghi, 2007, 15).

La Pedagogía es un propósito en sí misma, a saber: la orientación humana íntegra del hombre, la filosofía del hombre y el hacer de la sociedad. En esta relación hombre-sociedad es donde toma cuerpo la Pedagogía. «Los antiguos tenían la convicción de que la educación y la cultura no constituyen un arte formal o una teoría abstracta, distintos de la estructura histórica objetiva de la vida espiritual de una nación» (Jaeger, 2). 
Lo anterior orienta el propósito del presente escrito: exponer el planteamiento pedagógico que aporta el francés David Emilie Durkheim, desde la Sociología de la Educación, para hacer efectivo el proyecto que la Tercera República Francesa hubo de forjarse sobre la nueva sociedad y el nuevo ser social que pretendía. Para tal propósito, se examinan los fundamentos conceptuales que configuran el planteamiento sociológico del autor y su relación con un proyecto unificado teórico-práctico de sociedad y de nuevo ser social. Esto es un abordaje metodológico propiamente durkheimiano, de igual forma que lo propone al referirse a la educación en Esparta y, por supuesto, a la francesa (Durkheim, 1979).

Es necesario explicar las causas, y sobre todo las leyes sociales que conducen al territorio francés para que sufra, en principio, una radical transformación en 30 años como no lo había padecido en diez siglos medievales. Y sobre esto, corresponde advertir las consecuencias mal dejadas por la Revolución Francesa: la anarquía moral e intelectual. De esta preocupación propiamente comteana se apropia Durkheim, plasmándola en ideas que lo hacen constante deudor de su padre intelectual, incluso desde su tesis doctoral de secundaria (Lukes, 1984). La heterogeneidad anárquica representa un peligro para la recién nacida nación francesa (Tercera República), pues incentiva el subversivo pensamiento y libre examen y, por tanto, fomenta contrariar la preciada tradición de Francia (Durkheim, 1979, 76).

Durkheim es obra de y potencializó a la Tercera República Francesa, la que no puede ser sino «una república de profesores y maestros», además sin republicanos (Lepenies, 1994, 45). Derrotada la Comuna, los valores de solidaridad y los mecanismos de autoridad deben garantizar lo que a los franceses del momento tanto les preocupaba que se fuera a revolucionar de nuevo, máxime si la población en gran mayoría pretendía ser intelectual y científica: esto es, la tradición. Solidaridad, autoridad y tradición terminan por ser ejes conceptuales y preocupaciones prácticas de la obra pedagógica de Durkheim, sin los cuales no es comprensible en conjunto su Sociología de la Educación.

\section{LA CONDICIÓN: LA PEDAGOGÍA}

El interés que aún suscita Durkheim, particularmente respecto de la concepción de la Pedagogía, es que sus trabajos en este campo representan para la actualidad, como los anteriores a él para su madurez intelectual, «documentos del espíritu del tiempo» (Durkheim, 1979, 192). Esta es una noción muy alemana para un francés, pero advierte sobre el poder clásico de sus interpretaciones para los hechos contemporáneos.

Entre 1887 y 1902, Durkheim enseña en la Facultad de Letras de Burdeos, lo cual permite que maduren sus ideas en torno a la Pedagogía, como lo posibilita su apoyo en 1902 a la cátedra de Ciencia de la Educación, experiencias que le proporcionan un cierre de ciclo teórico-práctico para aportar decididamente al proyecto francés de sociedad.

Para Durkheim, la Pedagogía se ubica en el ámbito de la concepción sobre la educación, y no en la práctica; mientras la Pedagogía es intermitente, la educación es continua. Con esta perspectiva propone que el educador sea capaz de determinar lo que debe ser la práctica educativa, que logre definir e implementar principios de conducta; esto hará de Durkheim un demiurgo moral de la Sociología para la sociedad francesa.

También se puede señalar esto en una concepción más elaborada: la Pedagogía «es la reacción sistemática de [la ciencia especulativa de la educación] sobre [la actividad educativa en sí misma], la obra de reflexión que busca, en los resultados de la psicología y 
la sociología, principios para la conducta o para la reforma de la educación» (Durkheim, $1979,23)$. Cabe advertir que la reforma educativa era necesaria en cuanto el nuevo proyecto diseñado de sociedad francesa implicaba hacer de Francia un país claramente científico y político. El proyecto inicia con la dirección de Jules Ferry, quien promueve campañas de alfabetización: «se había vuelto obligatoria la asistencia a la escuela primaria, y gratuita la enseñanza primaria en las instituciones educativas del Estado» (Lepenies, 1994, 39).

Durkheim, en este punto de avance del proyecto de la Tercera República Francesa y de su madurez intelectual sobre la Pedagogía, se encuentra claramente al servicio del proyecto de sociedad a realizar, y para ello, una vez pensado el contexto, los medios y fines de la educación a la luz de la Pedagogía, le queda por aportar la legitimidad sociológica sobre el elemento práctico y fundamental para hacer real el proyecto educativo: la autoridad.

\section{EL MEDIO: LA EDUCACIÓN}

Si administrar bienes de salvación es propio de la Iglesia, Durkheim adapta una versión laica de esta idea adaptándola a la educación; se logra el paso del sacerdote al maestro, de profesar obediencia a la institución religiosa para tenerla ahora a la educativa. La Iglesia católica forja a imagen y semejanza un modelo de hombre, así pues a la educación le corresponde igual, para lo cual cabe siempre considerar de nuevo «el espíritu del tiempo», a sabiendas que "cada tipo de pueblo tiene la educación que le es propia y que puede servir para definirlo con el mismo derecho que su organización moral, política y religiosa» (Durkheim, 2002, 29). El «modelo humano» que la sociedad francesa de la Tercera República necesita, solo ella puede diseñarlo y hacerlo efectivo en la práctica, de igual manera que la Edad Media y el Renacimiento forjaron cada uno el que les correspondía: los primeros con «alumnos dialécticos», estos «se impusieron como fin hacer humanistas» (Durkheim, 1979, 175).

Durkheim se hace intérprete de su tiempo y cree entender que la sociedad necesita homogeneización y solidaridad. El fin de la educación es construir este ser social homogéneo, solidario y obediente que perpetúe la tradición. No es propio de la educación la individualidad, el libre examen, pues estos «son inútiles y hasta peligrosos» (Durkheim, $1979,76)$ para con la tradición; lo que a esta le corresponde es ser «el medio con que la sociedad renueva perpetuamente las condiciones de su propia existencia». Acaso, pregunta Durkheim, «¿Puede vivir la sociedad sin que exista entre sus miembros una suficiente homogeneidad?», la respuesta es inequívoca: no puede vivir, por ello la responsabilidad destacada de la educación es perpetuar y fortalecer «esta homogeneidad, fijando de antemano en el alma del niño las semejanzas esenciales que supone la vida colectiva» (Durkheim1979, 147).

El proyecto moral que propone Durkheim queda claro: formar un ser social homogéneo que no subvierta la tradición, por medio de la socialización de la generación adulta a la más joven, a partir de la autoridad que la primera representa sobre esta. En síntesis, hacer de los individuos egoístas, seres con vida «moral y social».

Durkheim es sumamente cuidadoso con cada una de las categorías conceptuales con que trabaja, razón por la que advierte necesario precisar la de «ser social». Al respecto, afirma que el ser social es un conjunto de creencias religiosas, de carácter práctico-moral, de tradiciones naturales o profesionales y de «opiniones colectivas de todo género» (Durkheim, 1979, 71). Con base en esto, aporta la definición de educación: «acción ejercida por las generaciones 
adultas sobre las que todavía no están maduras para la vida social», siendo su objeto, continúa el heredero de la tradición antiilustrada, «suscitar y desarrollar en el niño cierto número de estados físicos, intelectuales y morales que exigen de él, la sociedad política en su conjunto y el medio especial, al que está particularmente destinado» (Durkheim, 1979, 70).

La escuela es el medio moral más efectivo con que cuentan los gobiernos centrales de un país para promover y realizar sus proyectos de orden y progreso, idea comteana ya en consolidación, con la participación de Durkheim, en la Tercera República Francesa ${ }^{2}$. Si la educación cumple el propósito antes señalado, es más porque ella tiene vida real y, sobre todo, práctica, es decir, porque existe en la sociedad misma como hecho social. La educación es una cosa, un hecho social con las connotaciones que expresa Durkheim en Las reglas del método sociológico. De nuevo, Comte en el ambiente: la cientificidad observable, medible y categorizable de lo social, objetivado esto con y en la sociología de Durkheim, quien sobre todo asume la responsabilidad de hacer efectivo el espíritu científico en el campo de la educación, es decir, hacer de esta un proyecto moral laico y racionalista, y como dato analizable, explicable y comparable. Concluye Durkheim: «cuanto más se conoce la naturaleza de las cosas, más probabilidades hay de utilizarla eficazmente» (Durkheim, 1979, 25).

En la medida que se conozca la naturaleza de la educación, el gobierno francés, y Durkheim como su pedagogo, logrará poner en marcha el proyecto moral colectivista caracterizado por la cualidad cohesionadora y el poder coercitivo de la sociedad contra las formas individuales. El individuo «no puede crear ni destruir, ni transformar a su gusto» (Durkheim, 1979, 63); solo el poder de la sociedad hecha conciencia colectiva lo puede, si acaso, y gracias todo ello a la educación, la que termina por adoptar una «fuerza generalmente irresistible». No se educa a voluntad, es la educación con la propia fuerza coercitiva la que lo determina, con lo que garantiza la convivencia conforme a la tradición ${ }^{3}$ (Durkheim, 1979).

El orden social no corre riesgo, la tradición es inmune a las formas modernas de libertad individual y la estabilidad política se garantiza por ser el gobierno central quien imprime el ritmo de acción a las escuelas con las continuas inspecciones. El maestro en la clase y el gobierno ${ }^{4}$ en la sociedad, son las respectivas autoridades quienes certifican la configuración del nuevo ser social homogéneo, solidario y obediente. Queda claro que educar es asunto de ejercer autoridad con miras a la organización y el orden de la sociedad.

2 Al respecto, afirma Wolf Lepenies (1994) al referirse a la reforma educativa en el marco de la Tercera República: «El anticlericalismo también dejó su sello en la reforma universitaria; en lugar de la religión debía estar la ciencia, y en lugar de la metafísica la doctrina moral. Cual fieles discípulos de Comte, los republicanos parecían hacer todo lo posible por convertir en realidad la ley de los tres estados» (p. 39).

3 Para los ingleses es clara la reivindicación de la libertad individual, siendo John S. Mill su mayor representante. Reivindicación que se destaca, por ejemplo, en la maravillosa obra ensayística de Paul Hazard (1982): «y aun fuera de esas venturosas islas, los niños son dueños de su persona. Se apartan de la gente mayor y dejan que siga su camino sin creerse obligados a irle a remolque, como ocurre aquende el Océano» (p. 176).

4 Así destaca Durkheim (1974) el poder del Estado: «el Estado es un órgano especial encargado de elaborar ciertas representaciones que valen para la colectividad. Estas representaciones se valen de otras representaciones colectivas por su alto grado de conciencia y reflexión» (p. 95). 


\section{EL PROPÓSITO DE LA PEDAGOGÍA: LA SOCIEDAD}

Negar al individuo es afirmar la sociedad. Combatir la anomia moral e intelectual preserva el orden social; y para esto, la autoridad del maestro y la del gobierno es la única eficaz, de otra manera la sociedad no sería libre, pues esta, afirma Durkheim, es hija de aquella. De dudosa aceptación, pero son los planteamientos que caracterizan su conservadora tradición sociológica.

Ha quedado claro que la educación en Francia, la del nuevo proyecto de sociedad y la del ser social, es obra natural de las condiciones materiales y del marco de ideas de la propia sociedad francesa. Así, «cada tipo de pueblo tiene su educación, que le es propia y que puede servir para definirlo con tanto fundamento como su organización moral, política y religiosa» (Durkheim, 1979, 10-11). Queda por redondear el proyecto moral y sagrado de la sociedad sobre, y gracias a, el individuo.

Garantizar el orden y la cohesión social, la solidaridad e integración colectiva es el resultado de una disciplina moral que se hace real en el «cuerpo de reglas que prescriben al individuo lo que debe hacer para no atentar contra los intereses colectivos, para no desorganizar la sociedad de la que forma parte» (Durkheim, 1974, 57). Esto es la educación: una disciplina moral que va al rastre contra las formas individuales y conflictivas que, al pensar de Durkheim, amenazan la forma moderna e Ilustrada de la sociedad. Corresponde, por tanto, fortalecer la interiorización moral colectiva.

Durkheim -a riesgo de repetir lo expuesto, y como vocero de la política de la Tercera República Francesa y en la condición de académico de la Nueva Sorbona- insiste en la facultad creadora de la educación desde la autoridad que esta reviste, con miras sin más al «interés colectivo» ordenador y conservador que prevenga la promoción de «creencias particulares», con las que «la grande alma de la patria se dividiría y se resolvería en una multitud incoherente de pequeñas almas fragmentarias, en conflicto unas con otras» (Durkheim, 1979, 83).

El perfil pedagógico de la sociedad francesa para el siglo XIX y primeros decenios del XX adopta claridad, con un Durkheim decididamente agente de la socialización del individuo, para que este devenga en ser social, lo que de suyo presenta dificultades prácticas y potencializa errores teóricos. Al generalizarse un «misticismo de la colectividad» (Lepenies, 1994, 46), la reivindicación del proyecto autónomo revela su infertilidad, de igual manera que, al mistificarse el papel de la educación y al elevarse la Sociología a ciencia moral, los académicos investigadores terminarán por ser «reformadores fanáticos» que, a fuerza de la teoría, encuadran la diversidad de la vida social e individual, sacrificando «todo a su visión de una conciencia colectiva que no expresaba nada más allá de la concepción del mundo por la clase media burocratizada a fondo, y con ello por los cadres [marcos] en que se apoyaba la República» (Lepenies, 1994, 62).

\section{CONCLUSIONES}

El cuerpo conceptual y metodológico forjado en una sociedad determinada en tiempo y lugar, habrá de responder al ejercicio autónomo de que aquélla asuma la labor de pensarse a sí misma y de comprender su propia dinámica como sociedad. Durkheim, fiel a su concepción pedagógica y a sus intereses prácticos educativos, ha pretendido ser el educador de Francia al identificar, interpretar y orientar las necesidades morales de su tiempo. Afirmar esto no legitima los vacíos conceptuales y menos las consecuencias 
negativas en la práctica, pero sí resalta la importancia de aportar pedagogías y prácticas educativas con base en las necesidades de la misma sociedad, y no en la importación aconceptual y ahistórica de modelos implementados a ciegas.

Con Durkheim el lector puede comprender que el quehacer educativo y sociológico no está desprovisto de intereses particulares. La esterilización intelectual promulgada como neutralidad ya de suyo es muestra de elegir una posición, ante todo de consecuencias políticas. Durkheim favorece un proyecto de sociedad -tal vez el único que para el momento de la Tercera República Francesa era plausible defender-, como en su momento le correspondió a John S. Mill en Inglaterra y a Fichte y Hegel, por ejemplo, en Alemania. El hecho de pensar la Pedagogía comprendida en el espíritu del tiempo, posibilita un llamado local a pensarnos en nuestra dinámica de vida social y, por lo tanto, «elaborar» una perspectiva pedagógica y una práctica educativa que respondan a las necesidades particulares de la sociedad.

En síntesis, desde Durkheim y a fuerza de sus conservadores planteamiento pedagógicos, corresponde comprender que «cada sociedad se forja un cierto ideal de hombre. Es este ideal "lo que constituye el polo de la educación"» (Durkheim, 1979, 10). El ideal del tiempo presente no puede ser aquel que desvanezca la autonomía del individuo, menos aún el que refuerce la autoridad seca de instituciones que, por legales que sean, no hacen lo legítimo.

\section{REFERENCIAS}

Abbagnano, N. y Visalberghi, A. (2007). Historia de la pedagogía. Madrid: Fondo de Cultura Económica.

Carmona Sánchez, L. A. (2015). Neuroeducación: enseñar en el siglo XXI. Monografías Asociación Educar. Recuperado de: http://www.asociacioneducar.com/monografias-docente-neurociencias/monografia-neurociencias-luis.alberto.carmona.sanchez.pdf

Durkheim, E. (1979). Educación y sociología. Bogotá: Linotipo.

Educación como socialización. (1976). Salamanca: Ediciones Sígueme.

(1974). Lecciones de sociología. Buenos Aires: La Pléyade.

(2002). La educación moral. Madrid: Morata.

Hazard, P. (1982). Los libros, los niños y los hombres. Barcelona: Juventud.

Jaeger, W. (1980). Paideia: los ideales de la cultura griega. México: Fondo de Cultura Económica.

Lepenies, W. (1994). Las tres culturas. La sociología entre la literatura y la ciencia. México: Fondo de Cultura Económica.

Lukes, S. (1984). Emile Durkheim. Su vida y su obra. Estudio histórico-crítico. Madrid: Siglo Veintiuno.

Pérez Tapias, J. A. (1995). Filosofía y crítica de la cultura. Madrid: Trotta. 